УдК 631.67

https://doi.org/10.32634/0869-8155-2022-355-1-114-117

Оригинальное исследование/Original research

\section{Дедова Э.Б.}

ФГБНУ «ВНИИГиМ им. А.Н. Костякова», 127434 Россия, г. Москва, ул. Большая Академическая, д. 44

E-mail: elviola27@gmail.com

Ключевые слова: аридная зона, орошение, минерализация, почва, солеустойчивые куль туры, удобрения, продуктивность

Для цитирования: Дедова Э.Б. Технология использования минерализованной воды для полива кормовых культур. Аграрная наука. 2022; 355 (1): 114-117.

https://doi.org/10.32634/0869-8155-2022-355-1-114-117

Конфликт интересов отсутствует

\section{Elvira B. Dedova}

All-Russian Research Institute of Hydraulic Engineering and Land Reclamation named after A.N. Kostyakov, Bolshaya Akademicheskaya street 44, Moscow, 127434, Russia E-mail: elviola27@gmail.com

Key words: arid zone, irrigation, mineralization soil, salt-resistant crops, fertilizers, productivity

For citation: Dedova E.B. Technology of use of mineralized water for forage crops irrigation. Agrarian Science. 2022; 355 (1): 114-117. (In Russ.)

https://doi.org/10.32634/0869-8155-2022-355-1-114-117

There is no conflict of interests

\section{Технология использования минерализованной воды для полива кормовых культур}

РЕЗЮМЕ

Актуальность. Территория Республики Калмыкия относится к европейской части аридного пояса Российской Федерации, где ощутима большая потребность в водных ресурсах на социально-бытовые и промышленные нужды, на развитие мелиорации земель, обводнение пастбищ и орошаемое земледелие. Естественная гидрографическая сеть развита очень слабо. Местный поверхностный паводковый сток аккумулируется в многочисленных малообъемных водоемах (озерах, прудах и водохранилищах). Качественный состав этих вод отличается относительно высоким содержанием солей (степень минерализации колеблется от 2 до 6 г/л) Полезный сток воды в зависимости от влагообеспеченности года варьирует от 0,5 до 30 млн м ${ }^{3}$, что позволяет организовывать на базе данных водных объектов небольшие участки орошения оазисного (очагового) типа. Наибольшие объемы дренажно-сбросных вод формируются на Сарпинской, Черноземельской и ПравоЕгорлыкской гидромелиоративных системах, что дает возможность их повторного использования. Для предотвращения негативных процессов, развивающихся на почвах аридной зоны при орошении культур водами повышенной минерализации, актуальной является разработка технологии их использования.

Методы. Полевые многолетние исследования по разработке экологически безопасной технологии выращивания кормовых культур при поливе минерализованными водами проводились на зональных светло-каштановых солонцеватых легко- и среднесуглинистых и бурых полупустынных почвах. Объектами исследований являлись агроценозы многолетних (Medicago sativa L., Elytrigia elongata (Host) Nevski) и однолетних кормовых культур (Amaranthus paniculatus, Sorghum sudanense, Sorghum saccharatum (L.) Pers.). Способ полива - дождевание, минерализация оросительной воды 4-6 г/л. Режим орошения поддерживался на уровне не ниже предела передвижения воды в виде капиллярных токов (75-80\% НB).

Результаты. Разработаны агротехнологические мероприятия по созданию оптимальных экологических условий выращивания кормовых культур при орошении водами повышенной минерализации, включающие: правильный выбор участка, подбор солеустойчивых культур и освоение мелиоративно-кормовых севооборотов, параметры водного и питательного режимов почвы, обеспечивающие урожайность сена на уровне $12-15$ т/га.

\section{Technology of use of mineralized water for forage crops irrigation}

\section{ABSTRACT}

Relevance. The Republic of Kalmykia is located in the european part of the arid belt of the Russian Federation, in which there is the water demand for social and industrial needs, for land reclamation development, for pasture lands watering and irrigated agriculture. The natural hydrographic network is very poorly developed. Local surface flood runoff is accumulated in numerous small water bodies (lakes, ponds and reservoirs). The qualitative composition of these waters is distinguished by a relatively high salt content (the degree of mineralization ranges from 2 to $6 \mathrm{~g} / \mathrm{l}$ ). The useful water runoff, depending on the average moisture content per year, varies from 0.5 to 30 million $\mathrm{m}^{3}$, which makes it possible to organize small areas of irrigation of the oasis (focal) type based on a database of water bodies. The largest volumes of drainage and waste water are formed in the Sarpinskaya, Chernozemelskaya and Pravo-Egorlykskaya irrigation and drainage systems, which makes it possible to reuse them. To prevent negative processes developing on the soils of the arid area when crops are irrigated with highly saline water, it is important to develop a technology for their usage.

Methods. Long-term field studies on the development of an environmentally safe technology for growing fodder crops under irrigation with mineralized waters were carried out on zonal light-chestnut solonetz, light and medium loamy and brown semiarid soils. The objects of the research were agrocenoses of perennial (Medicago sativa L., Elytrigia elongata (Host) Nevski) and annual fodder crops (Amaranthus paniculatus, Sorghum sudanense, Sorghum saccharatum (L.) Pers.). The irrigation regime was maintained at a level not lower than the limit of water movement in the form of capillary currents $(75-80 \% \mathrm{HB})$.

Results. Agrotechnological measures have been developed to create optimal environmental conditions for growing fodder crops with highly saline water irrigation, including: the right choice of site, the selection of salt-resistant crops and the development of reclamation-forage crop rotations, the parameters of the water and nutrient regimes of the soil, ensuring hay yields at the level of $12-15 t /$ ha. 
Дефицит пресных водных ресурсов в аридных территориях диктует необходимость разработок адаптивных технологий утилизации и применения вод повышенной минерализации, в том числе коллекторно-дренажных и дренажно-сбросных, используемых для полива сельскохозяйственных культур. Существуют различные методы и способы очистки и улучшения качества ирригационной воды: химическая мелиорация, электромелиорация, опреснение, коагуляция, омагничивание, рассоление (зимнее дождевание) и другие. Коллекторно-дренажные воды после обессоливания и очистки могут терять свойства полноценной, кондиционной воды. Для восстановления продуктивных свойств воды, предназначенной для орошения сельскохозяйственных культур, предусматривается кондиционирование, включающее аэрацию, регулирование $\mathrm{pH}$, химическую мелиорацию с целью предотвращения осолонцевания и содообразования почв, а также внесение микроэлементов, необходимых для растений [1-3].

Решение проблемы связано в первую очередь с использованием дренажно-сбросных вод, объем которых по стране составляет более 6,0 млрд м ${ }^{3}$ в год [2, 5]. В Республике Калмыкия в условиях дефицита пресной воды использование высокоминерализованных вод (4-6 г/л) для орошения солеустойчивых культур с применением удобрений и мелиорантов возможно на почвах с легким гранулометрическим составом и хорошей естественной дренированностью территории. Соблюдение специальной технологии позволяет получать стабильные урожаи кормовых культур порядка 5,0-6,0 т/га сена и более, что в 10-15 раз больше, чем на богаре [4, 6-11].

\section{Условия и методы проведения исследований}

В аридных условиях Республики Калмыкия исследованиями $[1,2,4]$ выявлено, что воды местного стока, аккумулированные в водоемах (прудах, озерах и водохранилищах), имеют минерализацию в пределах от 1,5 до 6,0 г/л и ярко выраженную внутрисезонную амплитуду колебаний с возрастанием от весны к осени. Почвенный покров данной территории представлен светло-каштановыми суглинистыми почвами в комплексе с солонцами (от 30 до 40\%). В связи с этим использование для полива этих вод, имеющих хлоридно-сульфатный и сульфатно-хлоридно-магниево-натриевый химический состав, потенциально опасно с точки зрения развития процессов вторичного засоления и осолонцевания.

Для улучшения качества минерализованных вод и экологически безопасного их применения предложено вносить химический мелиорант - фосфогипс - в дозах от 4 до 8 т/га. Половина его вносится в сухом виде под основную обработку почвы, а другая половина - с поливной водой. Применение средств химической мелиорации обеспечивает улучшение водно-физических и агрохимических свойств почвы: в почвенно-поглощающем комплексе доля обменного натрия уменьшается на 20-25\%, снижается плотность пахотного горизонта, улучшаются водопроницаемость и влагоемкость почвы, происходит накопление питательных веществ за счет растительных остатков и поступления в значительном количестве легкодоступного фосфора, интенсивней происходит процесс рассоления почвогрунта. При этом урожайность зеленой массы кормовых культур, таких как пайза, амарант, колумбова трава, мальва курчавая, подсолнечник ветвистый, сида многолетняя, козлятник восточный, донник желтый, сильфия пронзеннолистная, редька масличная - варьирует от 13,3 до 57,0 т/га [2, 4, 6].

Аналогичные опыты по орошению минерализованной водой проведены на каштановых суглинистых почвах в комплексе с солонцами (от 10 до 75\%) в долине р. Западный Маныч сухостепной зоны Калмыкии $[4,9]$. Исследования показали, что при минерализации воды на уровне 2,2-4,0 г/л в первые годы ее применения происходит увеличение содержания подвижных форм питательных элементов в почве. Однако параллельно происходят и негативные изменения - увеличивается количество в почвенно-поглощающем комплексе $\mathrm{Na}$ и $\mathrm{Mg}$.

\section{Результаты исследований и их обсуждение}

Анализ теоретических исследований и результаты полевых экспериментов [2-14] позволили разработать мероприятия по созданию оптимальных экологических условий при орошении культур водами повышенной минерализации:

- Правильный выбор участка, который должен располагаться на повышенных по отношению к уровню водоема элементах мезорельефа, относительно ровных, с наиболее легкими по гранулометрическому составу почвогрунтами. При этом необходимо проведение планировки поверхности почвы и приемов обработки, направленных на улучшение агрофизических и агрогидрологических свойств почвы.

- Подбор солеустойчивых культур и освоение мелиоративно-кормовых севооборотов, включающих до 60\% люцерны (пырея солончакового) 1-3-го года жизни, $20 \%$ суданской травы, 20\% однолетних ранних и поздних травосмесей.

- Проведение посева многолетних и однолетних трав с увеличенной (на 20-25\%) нормой сплошным способом в целях создания плотного травостоя, уменьшения испарения влаги и предотвращения подтягивания солей к поверхности почвы.

- Режим орошения культур-мелиорантов основывается на поддержании предполивной влажности почвы в корнеобитаемом слое на уровне не ниже предела передвижения воды в виде капиллярных токов, что способствует созданию нисходящих токов воды и выносу солей из корнеобитаемой зоны, предотвращению их реставрации в межполивные периоды (табл. 1). Так, в целях обеспечения безопасной почвенно-мелиоратив-

Таблица 1. Режим орошения культур-мелиорантов при поливе водой повышенной минерализацией (2-4 г/л)

Table 1. Irrigation mode of ameliorant crops with highly mineralized water irrigation (2-4 g/l)

\begin{tabular}{|c|c|c|c|c|}
\hline $\begin{array}{c}\text { Год жизни куль- } \\
\text { туры }\end{array}$ & $\begin{array}{c}\text { Урожайность } \\
\text { сена, т/га }\end{array}$ & $\begin{array}{c}\text { Поливная норма, } \\
\text { мм }\end{array}$ & $\begin{array}{c}\text { Число поливов, } \\
\text { шт. }\end{array}$ & $\begin{array}{c}\text { Оросительная } \\
\text { норма, мм }\end{array}$ \\
\hline \multicolumn{5}{|c|}{ Medicago sativa $L$. } \\
\hline Первый год & $3-7$ & $40-50$ & $6-10$ & $260-500$ \\
\hline $\begin{array}{l}\text { Второй-третий } \\
\text { год }\end{array}$ & $10-20$ & $40-60$ & $8-12$ & $360-720$ \\
\hline \multicolumn{5}{|c|}{ Elytrigia elongata (Host) Nevski } \\
\hline Первый год & $1,5-2,5$ & $25-30$ & $4-5$ & $110-138$ \\
\hline $\begin{array}{l}\text { Второй-третий } \\
\text { год }\end{array}$ & $8-15$ & $40-50$ & $6-7$ & $180-210$ \\
\hline
\end{tabular}


Рис. 1. Динамика содержания воднорастворимых солей в почве при поливе люцерны минерализованной водой (4-6 г/л)

Fig. 1. Dynamics of the content of water-soluble salts in the soil with mineralized water irrigation of alfalfa (4-6 g/l)

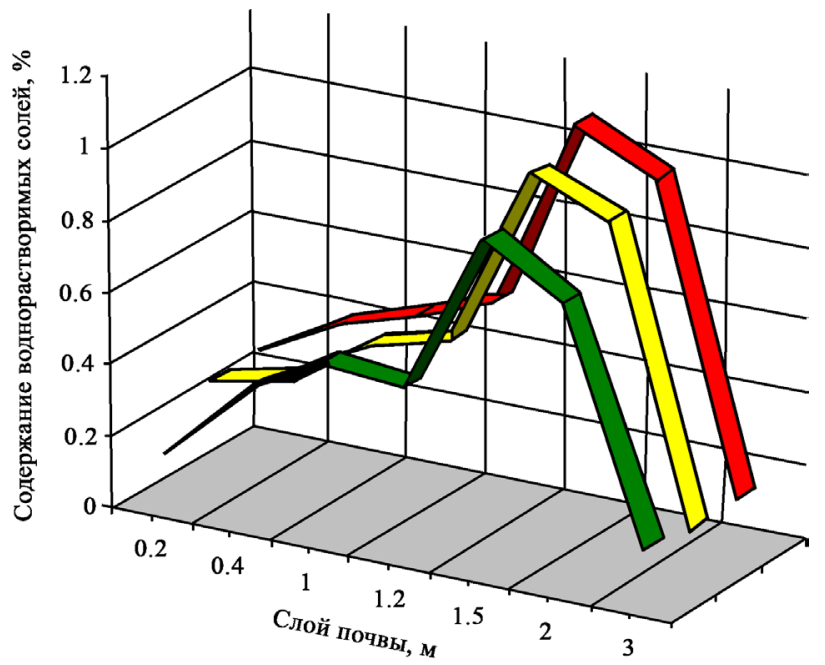

1-й год $\square$ 2-й год

3-й год

Рис. 2. Зависимость урожайности сена люцерны от уровня минерального питания и минерализации поливной воды

Fig. 2. Dependence of the alfalfa hay yield on the level of mineral nutrition and salinity of irrigation water

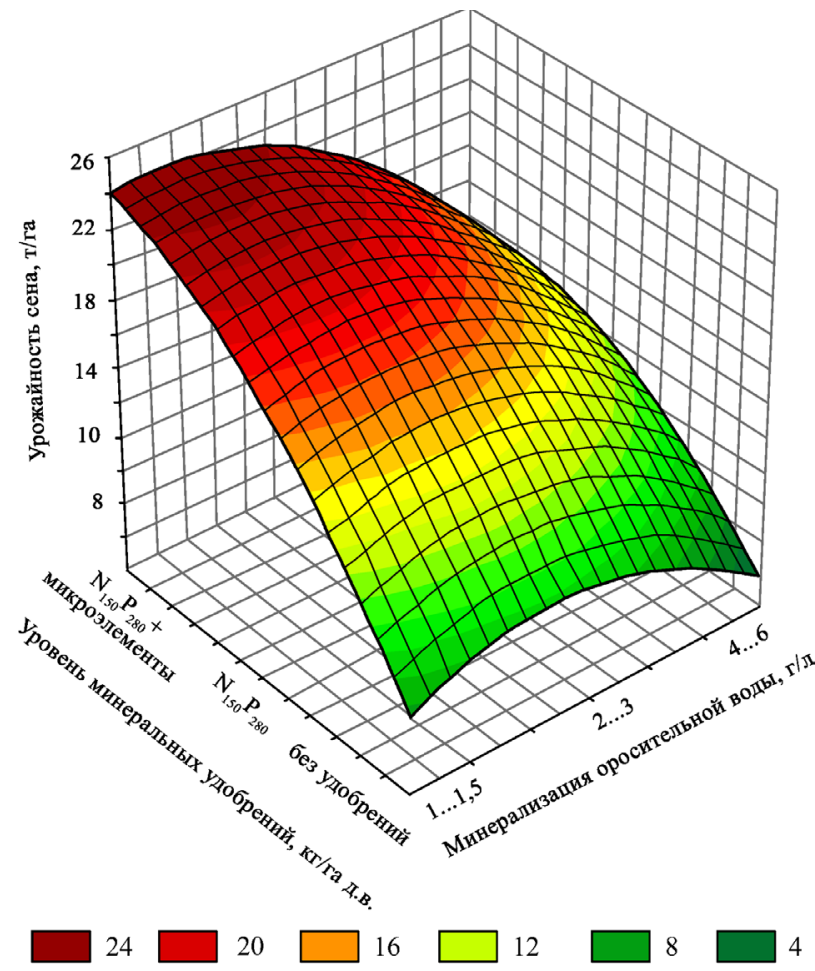

ной обстановки предполивная влажность почвы поддерживается на уровне 75-80\% НВ.

Применяемый режим орошения люцерны позволяет создать нисходящие токи воды, в результате которого соли вымываются за пределы метрового слоя почвы: ежегодно снижается содержание хлора на 32-33\%, натрия - на 5-10\%, а содержание сульфатов возрастает на 3-5\%. Кроме того, с надземной массой люцерны выносится с 1 га до 30 кг/га натрия, 64 кг/га сульфатов и 60 кг/га хлора, а с урожаем второго года вынос натрия достигает 75 кг/га, сульфатов - 160 кг/га, хлора 150 кг/га, что в 2,5 раза больше.

Результаты экспериментальных исследований показали, что за три года орошения минерализованной водой количество воднорастворимых солей в метровом слое почвы увеличилось на 12-15\% по сравнению с исходным содержанием. При этом наблюдается аккумулирование воднорастворимых солей в слое почвы 1,2-1,5 м (рис. 1).

Система удобрений кормовых культур при поливах минерализованными водами должна быть строго дифференцирована. Получение высоких урожаев кормовых культур должно обеспечиваться за счет улучшения пищевого режима почвы путем внесения минеральных удобрений с учетом того, что с каждой тонной сухой биомассы многолетних трав выносится большое количество питательных веществ, в частности по люцерне - 20-25 кг азота, 6-7 - фосфора и 17-20 - калия. На засоленных и слабогумусированных почвах эффективно внесение до 100 т/га навоза совместно с 4-5 т/га фосфогипса. Система удобрений под культуры-фитомелиоранты включает внесение фосфорных и калийных удобрений под основную обработку $\left(P_{10-20}\right)$ и внекорневые подкормки с первым поливом в начале вегетации и после проведения укосов.

Система удобрений люцерны посевной при поливе водами повышенной минерализации (4-6 г/л) включает припосевное внесение $\mathrm{P}_{20}$ и внекорневые подкормки с первым поливом в начале вегетации и после проведения укосов. Расчетная норма азотно-фосфорных удобрений составляет $\mathrm{N}_{150-170} \mathrm{P}_{280-320}$, микроэлементов: 1,5 кг меди, 0,1 кг цинка, 0,5 кг бора, 0,3 кг молибдена, 0,3 кг кобальта, 1,5 кг марганца в действующем веществе на один гектар. Микро- и макроудобрения вносят с помощью гидроподкормщика ГПД-50. При этом обеспечивается урожайность сена люцерны на уровне 1215 т/га (рис. 2).

Система удобрений под пырей включает внесение фосфорных удобрений под основную обработку $\left(P_{10-20}\right)$ и внекорневые подкормки с поливом в фазу кущения $\mathrm{N}_{40-50} \mathrm{P}_{20-30}$, в фазу колошения $-\mathrm{N}_{30-40} \mathrm{P}_{15-25}$, после проведения укосов надземной массы - $N_{20-30} P_{15-20}$.

Обеспечение дренированности орошаемой территории для увеличения скорости выщелачивания солей из корнеобитаемой зоны достигается за счет углубления существующей дренажно-сбросной сети до 3,0-3,5 м и создание временного дренажа с помощью щелевания и кротования (поперек рядков через 0,8-1,0 м и на глубину 0,3-0,4 м, ширина щелей 0,04-0,05 м).

\section{Выводы}

Установлено, что орошение сельскохозяйственных культур водами повышенной минерализации имеет свои особенности и включает приемы по созданию оптимальных условий водного и минерального питания культур, снижению негативного влияния засоления почвы и воды на растения и предотвращению ухудшения плодородия почвы. 


\section{ЛИТЕРАTУPA/ REFERENCES}

1. Borodychev V.V., Dedova E.B., Sazanov M.A. Water resources of the Republic of Kalmykia and measures to improve its water complex. Russian Agricultural Sciences. 2015; 5: 369-373.

2. Дедова Э.Б. Зональная шкала оценки качества поливных вод республики Калмыкия. Синергия. 2018; 1: 88-95. [Dedova E.B. Zonal scale for assessing the quality of irrigation water in the Republic of Kalmykia. Synergy. 2018; 1: 88-95. (In Russ.)].

3. Chhabra R. Soil salinity and water quality. New Delhi. 1996. $284 \mathrm{p}$.

4. Комплексное использование водных ресурсов Республики Калмыкия: Монография / Сост. и ред. С.Б. Адьяев, Э.Б. Дедова, М.А. Сазанов - Элиста: ЗАОр «НПП «Джангар», 2006. 200 c. [Kompleksnoe ispol'zovanie vodnykh resursov Respubliki Kalmykiya: Monografiya (Complex Use of Water Resources of the Republic of Kalmykia: Monograph), Ad'yaev, S.B. and Dedova, E.B., Eds., Elista: ZAO NPP Dzhangar, 2006. 200 p. (In Russ.)].

5. Шумаков Б.Б., Багненко В.И., Дудаков Н.К Орошение риса и кормовых культур дренажно-сбросными водами. Гидротехника и мелиорация. 1986; 4: 61-64. [Shumakov B.B., Bagnenko V.I., Dudakov N.K. Irrigation of rice and fodder crops with drainage and waste water. Hydraulic engineering and land reclamation, 1986; 4: 61-64. (In Russ.)].

6. Грициенко В.Г. Качество оросительной воды и приемы, устраняющие ее негативное влияние на почвогрунты и продуктивность агроценозов. Мелиорация земель Республики Калмыкия: Тр. ВНИИГиМ, Т. 97. М. 1997. С. 212 - 221. [Gritsienko V.G. Irrigation water quality and techniques that eliminate its negative impact on soils and productivity of agrocenoses. Land reclamation of the Republic of Kalmykia: Tr. VNIIGiM, Vol. 97. M. 1997. pp. 212 - 221. (In Russ.)].

7. Демкин О.В., Руднева Л.В. Приемы снижения негативного влияния полива минерализованными водами. В сб.: «Охрана почв Калмыкии и прилегающих территорий». Вып. 2. Элиста. 2003. C. 169-170. [Demkin O.V., Rudneva L.V. Techniques for reducing the negative impact of irrigation with mineralized waters. In the collection: "Protection of soils of Kalmykia and adjacent territories». Vol. 2. Elista. 2003. pp. 169-170. (In Russ.)].

8. Ковриго С.И., Макаров С.В. Дозы, сроки и способы внесения фосфогипса при орошении минерализованными водами. Мелиорация земель Республики Калмыкия: Тр. ВНИИГиМ, Т. 97. М. 1997. С. 202 - 212. [Kovrigo S.I., Makarov S.V. Doses, terms and methods of application of phosphogypsum during irrigation with mineralized waters. Land reclamation of the Republic of Kalmykia: Tr. VNIIGiM, Vol. 97. M. 1997. pp. $202-212$. (In Russ.)]

\section{OБ ABTOPAX:}

Дедова Эльвира Батыревна, доктор сельскохозяйственных наук, профессор РАН, ведущий научный сотрудник отдела экосистемного водопользования и экономики

https://orcid.org/0000-0002-0640-911X
9. Кравченко Ю.В., Руднева Л.В. Использование минерализованных вод для орошения в условиях сухостепнной зоны Калмыкии. Сб. науч. тр. Проблемы социально-экологического развития аридных территорий России. М. 2001. Том I. С. 323 - 327. [Kravchenko Yu.V., Rudneva L.V. The use of mineralized waters for irrigation in the conditions of the dry steppe zone of Kalmykia. Collection of scientific tr. Problems of socio-ecological development of arid territories of Russia. M. 2001. Volume I. pp. 323 - 327 (In Russ.)].

10. Дедова Э.Б., Сазанов М.А., Ковриго С.И., Сангаджиев Л.Н. Технология возделывания люцерны при поливе дренажно-сбросными водами в пустынной зоне Калмыкии. Сб. науч. тр. «Современные энерго- и ресурсосберегающие, экологически устойчивые технологии системы сельскохозяйственного производства». Вып.7. Часть ІІ. Рязань. 2003. С.98100. [Dedova E.B., Sazanov M.A., Kovrigo S.I., Sangadzhiev L.N. Technology of alfalfa cultivation during irrigation with drainage and waste water in the desert zone of Kalmykia. Collection of scientific tr. "Modern energy- and resource-saving, environmentally sustainable technologies of agricultural production system». Issue 7. Part II. Ryazan. 2003. pp.98-100. (In Russ.)].

11. Yashin V.M., Belosludtheva V.G., Dedova E.B. Water and saline management in semi-arid zone of Kalmykia. Research on irrigation and drainage. Republic of Macedonia. 2004; pp. 113121.

12. Дармонов Е.Д., Юлдашев Г., Турдалиев А.Т. Влияние поливов минерализованными водами на агробиологические особенности и урожайность пшеницы. Научное обозрение Биологические науки, 2021; 4: 23-27. [Darmonov E.D., Yuldashev G., Turdaliev A.T. Influence of irrigation with mineralized water on agrobiological features and wheat yield. Science Review. Biological Sciences, 2021; 4: 23-27 (In Russ.)].

13. Суванов Б.У. Использование минерализованных грунтовых вод при поливе сельскохозяйственных культур на засоленных землях. Актуальные проблемы современной науки. 2020; 5: 72-73. [Suwanov B.U. The use of mineralized groundwater for irrigation of agricultural crops on saline lands. Actual problems of modern science, 2020; 5: 72-73. (In Russ.)].

14. Искендеров М.Я. Влияние полива минерализованной водой на некоторые физиолого-биохимические процессы хлопчатника. Российская сельскохозяйственная наука. 2016 4: 27-30. [Iskenderov M.Ya. Impact of irrigation of cotton plant with mineralized water on physiological -biochemical processes. Russian Agricultural Sciences. 2016; 4: 27-30. (In Russ.)].

\section{ABOUT THE AUTHORS}

Dedova Elvira Batyrevna, Doctor of Agricultural Sciences, Professor of the Russian Academy of Sciences, Chief Scientist of the Department of Ecosystem Water Use and Economics https://orcid.org/0000-0002-0640-911X

\section{НОВОСТИ•НОВОСТИ•НОВОСТИ•НОВОСТИ॰}

\section{В РФ посевная площадь под кормовыми культурами будет увеличена до 13,9 млн гектар}

Посевные площади под сельхозкультурами в РФ составят 81,3 млн га в этом году, что на 0,9 млн га больше, чем в 2021 году, сообщил по итогам Всероссийского агрономического и агроинженерного совещания Минсельхоз России.

В текущем году среди ключевых задач - увеличение производства зерновых, сахарной свеклы, масличных, картофеля, овощей. Общую посевную площадь в России планируется расширить на 0,9 млн га, до 81,3 млн га: по зерновым и зернобобовым культурам - до 48 млн га, по кормовым культурам - до 13,9 млн га, по сахарной свекле - до 1,07 млн га.

Также существенно увеличится сев овощей и посадка картофеля. Озимыми культурами под урожай текущего года занято 19 млн га, при этом порядка 97\% посевов находятся в хорошем и удовлетворительном состоянии. Несмотря на неблагоприятные погодные условия прошлого года, в РФ собран достойный урожай основных сельхозкультур. По предварительным данным, достигнуты рекордные показатели в производстве масличных - 23,1 млн т, тепличных овощей $-1,4$ млн т, плодов и ягод - 3,9 млн т. Этому способствовала высокая обеспеченность аграриев материально-техническими ресурсами, в первую очередь удобрениями и техникой.

(Источник: ФИНМАРКЕТ) 